https://www.journal-imab-bg.org

Original article

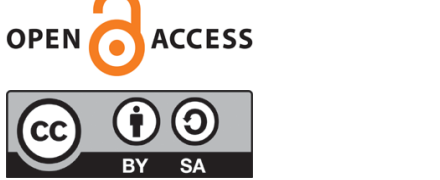

\title{
SAFETY OF TEETH EXTRACTIONS IN PATIENTS ON ACENOCOUMAROL THERAPY
}

\author{
Atanaska Dinkova, Hristo Daskalov. \\ Department of Oral Surgery, Faculty of Dental Medicine, Medical University \\ of Plovdiv, Bulgaria.
}

\begin{abstract}
Introduction: Studies evaluating bleeding risk in anticoagulated patients undergoing dental surgical procedures have been conducted for more than 50 years and are still ongoing. The aim of the present study is to clinically evaluate the bleeding after a simple teet extraction in patients on Acenocoumarol (Sintrom) monotherapy, with International Normalised Ratio (INR) below 2,5 at the time of extraction.

Material and Methods: In the study were included 60 patients, 44 men and 16 women, taking Sintrom, who underwent 95 simple teeth extractions at the Department of Oral Surgery - Faculty of Dental Medicine, Medical University Plovdiv, Bulgaria. In the study were included patients between 45 - 95 years, divided into Working group (WG) - 30 patients who received oral Acenocoumarol during the treatment; Control group (CG) - 30 patients who discontinued Acenocoumarol 72 hours prior dental treatment. Haemostasis was controlled by local measures: a gelatin sponge and /or wound suturing.

Results: In all patients, INR values obtained immediately prior to treatment were sub-therapeutic or therapeutic values up to 2,5 . Of all 60 patients, only 4 reported for secondary bleeding (up to 24 and up to 48 hours), which was self-limiting and no additional haemostasis was needed.

Conclusion: In patients receiving Acenocoumarol with INR values in the therapeutic range up to 2,5 , in the absence of other risk factors, simple tooth extraction can be safely performed without risk of uncontrolled post-extraction bleeding.
\end{abstract}

Keywords: anticoagulants, Sintrom, bleeding, haemostasis, tooth extraction, local haemostasis

\section{INTRODUCTION}

Studies evaluating bleeding risk in anticoagulated patients undergoing dental surgical procedures have been conducted for more than 50 years and are still ongoing [1].

Routine practice in the past was a discontinuation of the antithrombotic drug prior to tooth extraction - a general surgery approach where the integrity of big vessels is disturbed, and the risk of haemorrhage is high. Moreover, consulting physicians usually are not aware of the extent of oral surgery procedures and often overestimates the risk of bleeding $[2,3,4]$. These recommendations are made be- fore the standardization of oral anticoagulant therapy monitoring by INR [5].

Oral surgery and in particular simple dental extraction, differs from general surgery because the bleeding is only capillary, bleeding sites are easily accessible, and local haemostatic measurements are efficient to provide adequate haemostasis.

However, about $90 \%$ of post-extraction haemorrhage is due to excessive operative trauma, particularly to soft tissues; poor compliance with postoperative instructions; interference with the extraction socket or operation site (plasminogen activators are present in saliva and can thus cause fibrinolysis); inflammation at the extraction site, with resultant fibrinolysis; inappropriate use of analgesia with aspirin or NSAD; uncontrolled hypertension [6].

On the other hand thromboembolic events, including death, due to discontinuation of the anticoagulant therapy are described in the literature, and an increasing number of studies have confirmed the risk, which, although rare, is serious. This risk has to be balanced against the fact that there is no report of uncontrolled bleeding following dental extraction in continuing antithrombotic therapy.

Therefore, most authors, Dental and Heart associations today recommend maintaining therapeutic levels of antithrombotic drugs in most dental procedures, including teeth extractions, due to the fact that the risk of fatal embolism outweighs the risk of bleeding.

However, in practice, general and dental practitioners still overestimate the risk of bleeding and discontinue the therapy $[7,8]$.

The Aim of the present study is to clinically evaluate bleeding after a simple dental extraction in patients on Acenocoumarol (Sintrom) monotherapy.

\section{MATERIALS AND METHODS \\ Material}

In the study were included 60 patients taking Sintrom(Acenocoumarol), once daily for at least the past six weeks, referred to the Department of Oral Surgery Faculty of Dental Medicine - MU Plovdiv, for teeth extraction during the period 2014-2017 year. Patients were divided into Working group(WG) - 30 patients who received oral Acenocoumarol during the treatment. The control group (CG) - 30 patients who discontinued Acenocoumarol 
72 hour's prior dental treatment. The distribution of the patients in the groups was done through random selection.

Medical history was taken, clinical and radiographic examinations were performed at first visit.

Medical University of Plovdiv Ethics Committee approved the study protocol and the guidelines established in the Declaration of Helsinki were followed during the study.

The patients who participated in the study signed informed consent.

The Inclusion Criteria were: Adults over 18 years of age, orally taking Acenocoumarol (Sintrom) once daily for at least 6 weeks with teeth indicated for extraction; INR values within therapeutic limits $\leq 2,5$; Signed informed consent for participation in the study.

Exclusion Criteria: Pregnant; Concomitant antithrombotic therapy or therapy with other chemotherapeutic agents; Acute inflammation in the extraction site; Hypertension> 160/100 mmHg; Renal disease (chronic dialysis, renal transplantation or serum creatinine above 200 $\mu \mathrm{mol} / \mathrm{L}$;Diabetes; Liver impairment (chronic liver disease (e.g. cirrhosis) or bilirubin $>2$ times of normal in combination with AST/ALT/ALP> 3 times above normal); Stroke/ Heart attack less than 6 months ago; Valve prosthesis; Previous major bleeding (anaemia or bleeding predisposition); thrombocytopenia; haemophilia or other haemostatic disorders; High INR values $>2,5$; Additional therapy with cytotoxic drugs.

\section{Methods}

Hemostasis evaluation: INR was measured immediately prior to dental extraction with CoaguChekXS POC device (Roche Diagnostics, Indianapolis, IN).

Capillary blood was taken from all 60 patients up to 12 hours after the last administration of Acenocoumarol. The principle of the method using capillary whole blood is based on the amperometric determination of prothrombin time by INR after activation of coagulation with human recombinant thromboplastin. A drop of blood taken by finger prick is dripped onto the test strip, and the result is displayed on the screen of for approximately one minute. The linearity of the method of INR: $0.8-8.0$, reproducibility in time $\mathrm{CV}=4.5 \%$. Quality control is automatically performed for each test strip. The CoaguChek XS PT test strips are manufactured with a human recombinant tissue factor and have an International Sensitivity Index (ISI) of 1.0. (Figure 1).

Fig. 1.

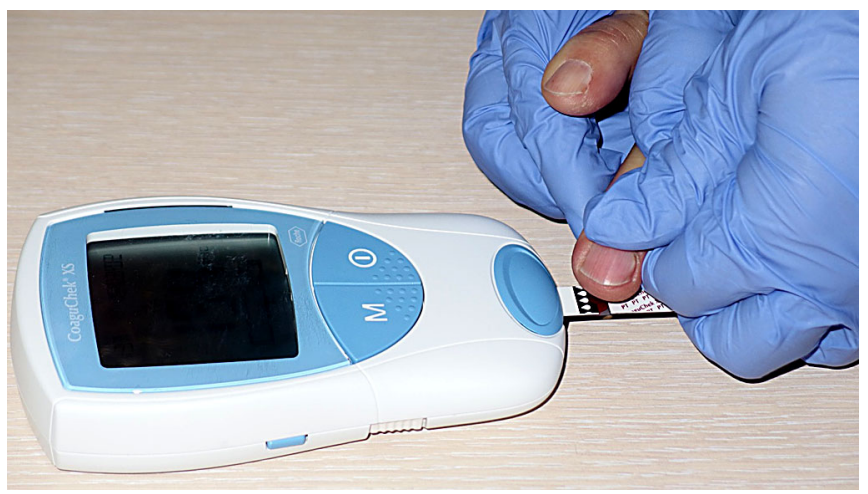

All patients received local anaesthesia with Ubistesin, 1:200,000, 3M-ESPE (Articaine - $40 \mathrm{mg} / \mathrm{ml}$ with Adrenaline - $0.006 \mathrm{mg} / \mathrm{ml}$, as maximum two cartridgesof $1.7 \mathrm{ml}$ were used. The injection was administered slowly after double negative aspiration.

We followed the Jimson's method[9], in which, for safely, without changing or interrupting the antithrombotic therapy, teeth extraction was limited up to 3 single-rooted teeth, up to 2 multi-rooted teeth and (if necessary) surgical extraction of 1 tooth in one visit. If more than 3 teeth had to be extracted, multiple visits were planned.

Surgical trauma was determined according to Bodner's scale [10] depending on the number and type of the extracted teeth: 1: forceps extraction of a single-rooted tooth; 2: forceps extraction of two rooted teeth; 3: forceps extraction of three rooted teeth; 4: surgical extraction of any tooth. For more than one extracted tooth, the degree of the trauma was calculated.

The extraction of the teeth was performed with minimal trauma by a standard surgical procedure using forceps and elevators. The initial control of post-extraction bleeding was achieved by mechanical compression of the wound with sterile gauze;mechanical compression by gauze soaked with 3\% Hydrogen Peroxide or adrenaline; placement of gelatin haemostatic sponge (Gepaspon) in the extraction socket (Figure 2).

Fig. 2.

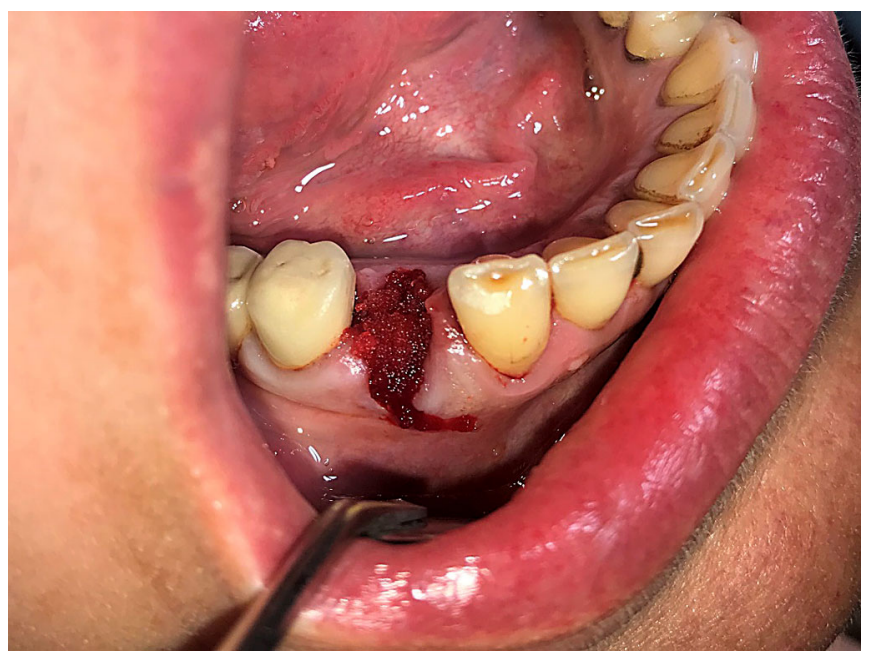

Suturing the extraction wound with non-absorbable sutures (polyamide 3/0 (Figure 3).

In case of bleeding, uncontrollable with local haemostasis, there was a readiness for parenteral haemostasis with freshly frozen plasma (i.v.) or vitamin $\mathrm{K}$ (1 mg, i.m.) $[11,12]$. 
Fig. 3.

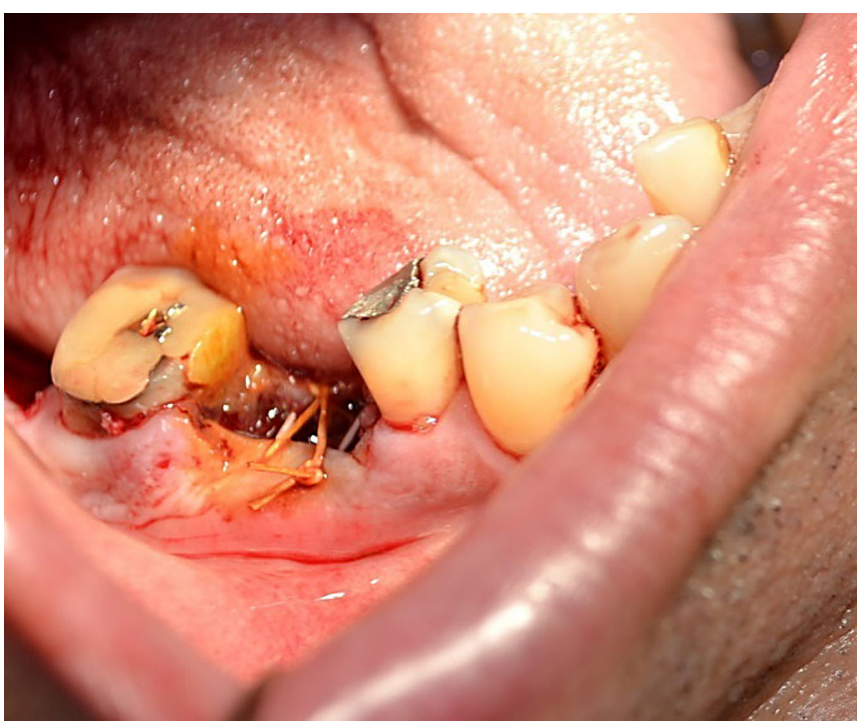

All patients were given detailed written postoperative instructions, the contents of which were verbally explained beforehand. Patients were asked to wait for a minimum of one hour within the clinic for control and detection of immediate bleeding. All patients returned for postoperative follow-ups at $24 \mathrm{~h}$ and 48 hours.

According to the methodologies of Canigral A, Lillis T, Madan GA, and others authors, clinical evaluation of haemostasis was made at 10th, 30th minute, at 24 and 48hour $[13,14,15,16,17,18]$. Positive bleeding was recorded in case of presence of liver clot or bleeding on probing (Figure 4).

Fig. 4.

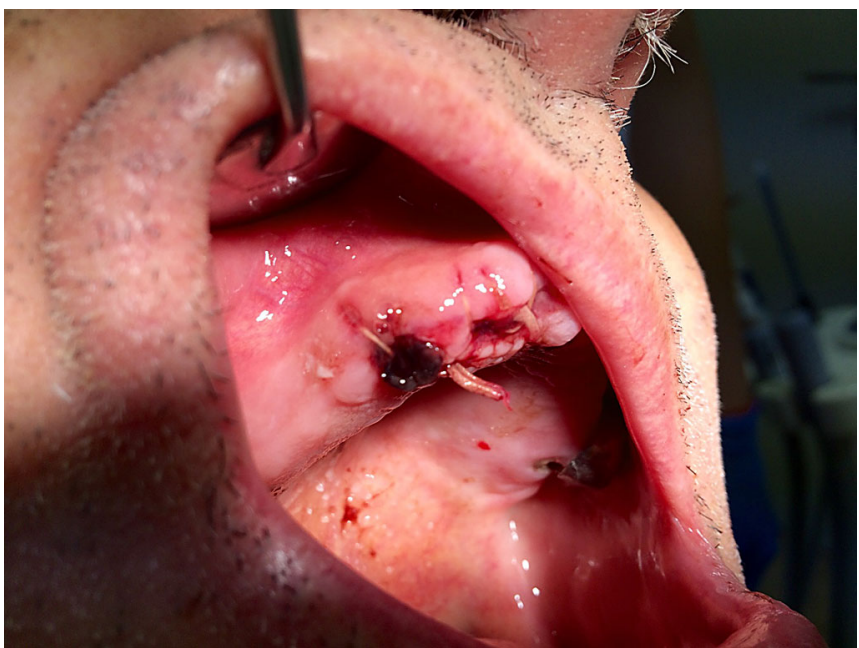

In the postoperative period for analgesia was prescribed Paracetamol 500 mg 2-3 times daily [19].

Statistical software SPSS v.22.0 (IBM, International) was used for statistical analysis.

Parametric methods for evaluation of the statistical relationships:

- Student's T-test; paired sample t-test; Analysis of variance (One-way ANOVA); Correlation analysis; Coefficient of linear correlation $\mathrm{r}$ (coefficient of Pearson)

Non-parametric methods for assessing the statistical dependencies:

- Fisher's exact test; Chi-square $\left(\chi^{2}\right)$ criterion; Test Mann-Whitney; Kruskal-Wallis Test. $\mathrm{P}$ values $<0.05$ were considered significant.

\section{RESULTS}

The study included 60 patients who were taking Acenocoumaroland who underwent 95 teeth extractions. The average age of the patients was $71.22 \pm 1.05$.

The youngest patient was 45 years old and the oldest- 95 years. In two groups the majority of the patients were on age between $61-70$ years, $(53.3 \%$ in $\mathrm{WG}$ and $36.7 \%$ in $\mathrm{CG}$ ), followed by the age group between $71-80$ years (36.7\% in both groups). Patients under 60 years were $3.3 \%$ in $\mathrm{WG}$ and $10 \%$ in CG. Patients over 80 years were $6.7 \%$ in WG and $16.7 \%$ in CG.There was no statistically significant difference among groups, in terms of age ( $p>0.05)$.

Gender distribution was $76.7 \%$ male and $23.3 \%$ female in the WG and $70 \%$ male and $30 \%$ female in the control group.

Indications for therapy with Sintrom:Prophylaxis of thromboembolism in heart arrhythmia $60.0 \%$ in WG and $30.0 \%$ in $\mathrm{CG}$; Ischemic heart disease (Myocardial Infarction, Stenocardia) at $6.7 \%$ in $\mathrm{WG}$ and $23.3 \%$ in $\mathrm{CG}$; Peripheral vascular disease $10.0 \%$ in $\mathrm{WG}$ and $16.7 \%$ in $\mathrm{CG}$; Cerebrovascular accident (Stroke) $6.7 \%$ in WG and $10.0 \%$ in CG; Coronary arterial bypass $3.3 \%$ in WG and $10.0 \%$ in $\mathrm{CG}$; Valvular heart disease (without prosthesis) $6.7 \%$ in WG; Heart failure $6.7 \%$ in WG; Percutaneous angioplasty and vascular stenting at $6.7 \%$ in $\mathrm{CG}$ and in ischemic cerebrovascular disease at $3.3 \%$ in CG.

Blood pressure values in patients in both groups were comparable: most patients had Hypertension I grade at the time of the treatment (50\% in WG and $56.7 \%$ in CG). Blood pressure with normal values had $26.7 \%$ in WG, and only $13.3 \%$ in CG and with Hypertension II grade had $23.3 \% \mathrm{WG}$ and $30.0 \%$ in the control group.

In all patients, INR was pre-operatively measured with CoaguChekXS. The INR in the whole group was between 1.0 and $2.5(1.80 \pm 0.63)$. In WG, INR was $1.20-$ 2.5(2.07). In CG, the INR was 1.0 - 2.4. (1.53). There was a statistically significant difference in the value of INR between the two groups. $(p<0.05)$.

Leading diagnosis requiring tooth extraction were retained roots at $45,23 \%$ in $\mathrm{WG}$ and half of those in CG $(50,94 \%)$, followed by teeth with third-grade mobility in $42,85 \%$ in WG and $39,62 \%$ in CG; and teeth with periapical lesions (11,9\% in WG, 9,43\% in CG).

Depending on the number of extracted teeth and the level of surgical trauma in $66.7 \%$ in WG and $50.0 \%$ CG was extracted 1 tooth, 2 teeth were extracted in $26.7 \%$ in WG and $23.3 \%$ in CG, three teeth, respectively in $6.7 \%$ in $\mathrm{WG}$ and $26.7 \%$ in CG. The trauma respectively was: 1 at $43.3 \%$ in $\mathrm{WG}$ and $30.0 \%$ in CG; 2 at $23.3 \%$ in $\mathrm{WG}$ and at $20.0 \%$ in CG; $3: 20.0 \%$ in WG and $36.7 \%$ in CG. Trauma 4 was inflicted at $10.0 \%$ in CG, trauma 5 at $10.0 \%$ in $\mathrm{WG}$ 
and $3.3 \%$ in CG; 6 at $3.3 \%$ in the WG.

The duration of extraction was also recorded. Most extractions were performed within $5 \mathrm{~min}$ - respectively $73.3 \%$ in $\mathrm{WG}$ and $60.0 \%$ in CG. Tooth extraction, lasting between $10-20 \mathrm{~min}$, occurred at $26.7 \%$ in $\mathrm{WG}$ and at $40.0 \%$ in CG. No longer treatment was performed.

For local haemostasis were used mechanical compression of the wound with sterile gauze, application of a gelatin sponge (Gelaspon) and/or suturing of the wound (Table 1).

Table 1. Local haemostasis.

\begin{tabular}{|l|c|c|c|c|}
\hline Local haemostasis & $\begin{array}{c}\text { No. of teeth } \\
\text { in } \mathbf{W G}\end{array}$ & $\boldsymbol{W G} \mathbf{( \% )}$ & $\begin{array}{c}\text { No. of teeth } \\
\text { in } \boldsymbol{C G}\end{array}$ & CG(\%) \\
\hline No additional haemostasis & 1 & $2,38 \%$ & 24 & $45,28 \%$ \\
\hline Gelaspon & 15 & $35,71 \%$ & 12 & $22,64 \%$ \\
\hline Suture & 5 & $11,90 \%$ & 5 & $9,43 \%$ \\
\hline Gelaspon and suture & 21 & $50,00 \%$ & 12 & $22,64 \%$ \\
\hline Total & 42 & $100 \%$ & 53 & $100 \%$ \\
\hline
\end{tabular}

A statistically significant difference was found, with a greater percentage of cases without the use of additional haemostasis in CG (P 0.000), compared with necessity of combined hemostasis with Gelatin sponge and suture in WG (P 0.015).

With regard to postoperative bleeding in the first 10 minutes, in $56.7 \%$ in $\mathrm{WG}$ and $33.3 \%$ in CG was observed prolonged bleeding but without statistically significant difference between the two groups (Table 2). Up to $30 \mathrm{~min}-$ utes bleeding was observed in $26.7 \%$ in $\mathrm{WG}$ and $6.7 \%$ in control, which was a statistically significant difference ( $p$ $<0,05)$

Late bleeding in the first 24 hours occurred in 1 patient in CG. Up to $48 \mathrm{hrs} 2$ patients in $\mathrm{WG}$ and 1 in $\mathrm{CG}$ reported slight bleeding - again without statistically significant difference between the two groups (Table 2). In all cases, bleeding was minor, self-limiting by gauze pressure, and no further aid was needed. No severe bleeding requiring hospitalization was encountered following the extractions.

Table 2. Post-extraction bleeding.

\begin{tabular}{|l|c|c|c|}
\hline Bleeding & $\begin{array}{c}\text { Working Group } \\
(\mathbf{n = 3 0})\end{array}$ & $\begin{array}{c}\text { Control Group } \\
(\mathbf{n = 3 0})\end{array}$ & p-value \\
\hline Post-extraction bleedinding in first $\mathbf{1 0}$ minutes & $17(57 \%)$ & $10(33 \%)$ & 0,071 \\
\hline Post-extraction bleedinding in first $\mathbf{3 0}$ minutes & $8(27 \%)$ & $2(7 \%)$ & 0,039 \\
\hline Late post-extraction bleedinding in first $\mathbf{2 4}$ hours & $0(0 \%)$ & $1(3 \%)$ & 0,326 \\
\hline Late post-extractionbleedinding in first $\mathbf{4 8}$ hours & $2(7 \%)$ & $1(3 \%)$ & 0,561 \\
\hline
\end{tabular}

\section{DISCUSSION}

The results showed that the majority of patients taking Sintrom were between 60 and 80 years of age.Some authors find a correlation between post-extraction bleeding and advanced age $[7,14]$. We also found a correlation between bleeding in the first $30 \mathrm{~min}$ and age.

Therapy usually is with long duration or permanent, which coincides with the literature [20]. In all patients, INR values obtained immediately prior to treatment were subtherapeutic or therapeutic values up to 2,5.

In all patients no more than 3 teeth were extracted, and hence the level of trauma was low, which was consistent with the recommendations of many authors for limiting the risk of post-operative bleeding by limiting the surgical trauma[10, 15, 21]. Also, extractions in most patients were short, which also can affect postoperative bleeding [22].

Only four patients reported late post-extraction bleeding, self-limiting by gauze pressure, and no further aid was needed which confirm the literature: local haemos- tasis (gelatin sponge and/or suturing) is enough to control post-extraction bleeding. [3, 9, 13 - 17].

No systemic haemostasis was needed, which coincides with the literature data [8, 11, 13, 23, 24].

\section{CONCLUSIONS}

1. In patients receiving Sintrom prolonged postbleeding bleeding,observed mainly in the first 10 minutes, is without a statistically significant difference between the patients continued or stopped the therapy.

2. A correlation between advanced age and prolonged post-extraction bleeding in patients receiving Acenocoumarol was established.

3. No correlation between the INR value within the therapeutic range of up to 2,5 and prolonged post-extraction bleeding was found.

4. Correlation between the duration of extraction and bleeding was found in patients receiving Acenocoumarol.

5. No electrocoagulation or parenteral haemostasis 
was used for bleeding control. Local haemostasis was sufficient to control bleeding in the study patients.

6. In patients on Sintrom monotherapy with INR †in a therapeutic range up to 2,5 , in the absence of other risk factors, simple tooth extraction can be performed, at the level of surgical trauma to the third degree, without the risk of uncontrollable post-extraction bleeding.

\section{REFERENCES:}

1. Askey JM, Cherry CB. Dental extraction during dicumarol therapy. Calif Med. 1956 Jan;84(1):16-7. [PubMed]

2. Antithrombotic Trialists' Collaboration. Collaborative Meta-Analysis of Randomised Trials of Antiplatelet Therapy for Prevention of Death, Myocardial Infarction, and Stroke in High Risk Patients. BMJ. 2002 Jan 12;324(7329):71-86. [PubMed] [Crossref]

3. Ardekian L, Gaspar R, Peled M, Brener B, Laufer D. Does low-dose aspirin therapy complicate oral surgical procedures? J Am Dent Assoc. 2000 Mar;131(3):331-5. [PubMed] [Crossref]

4. Eapen BV, Baig MF, Avinash S. An Assessment of the Incidence of Prolonged Postoperative Bleeding After Dental Extraction Among Patients on Uninterrupted Low Dose Aspirin Therapy and to Evaluate the Need to Stop Such Medication Prior to Dental Extractions. J Maxillofac Oral Surg. 2017 Mar;16(1):48-52. [PubMed] [Crossref]

5. Lemkin SR, Billesdon JE, Davee JS, Leake DL, Kattlove HE. Aspirin-induced oral bleeding: correction with platelet transfusion. A reminder. Oral Surg Oral Med Oral Pathol. 1974 Apr;37(4):498-501. [PubMed]

6. Hasegawa $\mathrm{T}$, Yanamoto $\mathrm{S}$, Tachibana A, Kojima Y, Koyama Y, Maeda M, et al. The risk factors associated with postoperative hemorrhage after tooth extraction: a multi-center retrospective study of patients receiving oral antithrombotic therapy. Oral Maxillofac Surg. 2017 Dec;21(4):397404. [PubMed]

7. Dinkova A, Atanasov D, Vladimirova-Kitova L. Opinion survey of the general practitioners in bulgaria regarding therapy with acetylsalicylic acid, clopidogrel and acenocoumarol in patients undergoing dental extrac- tions. J of IMAB. 2017 Oct-Dec; 23(4):1769-1772. [Crossref]

8. Wahl M, Pinto A, Kilham J, Lalla RV. Dental surgery in anticoagulated patients-stop the interruption. Oral Surg Oral Med Oral Path and Oral Rad. 2015 Feb;119(2):136-157. [PubMed]

9. Jimson S, Amaldhas J, Jimson S, Kannan I, Parthiban J. Assessment of bleeding during minor oral surgical procedures and extraction in patients on anticoagulant therapy. J Pharm Bioallied Sci. 2015 Apr; 7(Suppl 1): S134-S137. [PubMed]

10. Bodner L, Weinstein JM, Baumgarten AK. Efficacy of fibrin sealant in patients on various levels of oral anticoagulant undergoing oral surgery. Oral Surg Oral Med Oral Pathol Oral Radiol Endod. 1998 Oct;86(4):421-4. [PubMed]

11. Dhakal P, Rayamajhi S, Verma V, Gundabolu K, Bhatt VR. Reversal of anticoagulation and aanagement of bleeding in patients on anticoagulants. Clin Appl Thromb Hemost. 2017 Jul;23(5):410-415 [PubMed]

12. Salam S, Yusuf H, Milosevic A. Bleeding after dental extractions in patients taking warfarin. $\mathrm{Br} \mathrm{J}$ Oral Maxillofac Surg. 2007 Sep;45(6):4636. [PubMed]

13. Broekema FI, van Minnen B, Jansma J, Bos RR. Risk of bleeding after dentoalveolar surgery in patients taking anticoagulants. $\mathrm{Br} \mathrm{J}$ Oral Maxillof Surg. 2014 Mar;52(3):159.[PubMed]

14.Cañigral A, Silvestre FJ, Cañigral G, Alós M, Garcia-Herraiz A, Plaza A. Evaluation of bleeding risk and measurement methodsin dental patients. Med Oral Patol Oral Cir Bucal. 2010 Nov 1;15(6):e863-8. [PubMed]

15. Cardona-Tortajada F, SainzGómez E, Figuerido-Garmendia J, de
Robles-Adsuar AL, Morte-Casabó A, Giner-Muñoz F, et al. Dental extractions in patients on antiplatelet therapy. A study conducted by the Oral Health Department of the Navarre Health Service (Spain). Med Oral Patol Oral Cir Bucal. 2009 Nov 1;14(11):e588-92. [PubMed]

16. Lillis T, Ziakas A, Koskinas K, Tsirlis A, Giannoglou G. Safety of Dental Extractions During Uninterrupted Single or Dual Antiplatelet Treatment. Am J Cardiol. 2011 Oct 1;108(7):9647. [PubMed]

17. Madan GA, Madan SG, Madan G, Madan AD. Minor oral surgery without stopping daily low-dose aspirin therapy: a study of 51 patients. J Oral Maxillofac Surg. 2005 Sep;63(9): 1262-5. [PubMed]

18. Nooh N. The effect of aspirin on bleeding after extraction of teeth. Saudi Dent J. 2009 Jul;21(2):57-61. [PubMed] [Crossref]

19. Bajkin BV, Vujkov SB, Milekic BR, Vuckovic BA. Risk factors for bleeding after oral surgery in patients who continued using oral anticoagulant therapy. J Am Dent Assoc. 2015 Jun;146(6):375-381. [PubMed]

20. Agarwal N, Mahtta D, Rambarat CA, Elgendy I, Mahmoud AN. Optimum Antithrombotic Therapy in $\mathrm{Pa}$ tients Requiring Long-Term Anticoagulation and Undergoing Percutaneous Coronary Intervention. Biomed Res Int. 2018; 2018: 5690640.. [PubMed] [Crossref]

21. Wong H, Lovett N, Curry N, Shah K, Stanworth SJ. Antithrombotics in trauma: management strategies in the older patients. J Blood Med. 2017 Oct 4;8:165-174. [PubMed]

22. Halfpenny W, Fraser JS, Adlam DM. Comparison of 2 Hemostatic Agents for the Prevention of Postextraction Hemorrhage in Patients on Anticoagulants. Oral Surg Oral Med 
Oral Pathol Oral Radiol Endod. 2001 Sep;92(3):257-9. [PubMed]

23. Gröbe A, Fraederich M,Smeets R,Heiland M, Kluwe L, Zeuch Jet al. Postoperative bleeding risk for oral surgery under continued Clopidogrel antiplatelet therapy. BioMed Res Int. 2015; 2015:823651. [PubMed] [Crossref]

24. Hanken H, Tieck F, Kluwe L, Smeets R, Heiland M, Precht C, et al. Lack of evidence for increased postop- erative bleeding risk for dental osteotomy with continued aspirin therapy. Oral Surg Oral Med Oral Pathol Oral Radiol. 2015 Jan;119(1):17-9. [PubMed]

Please cite this article as: Dinkova A, Daskalov H. Safety of teeth extractions in patients on Acenocoumarol therapy. J of IMAB. 2020 Apr-Jun;26(2):3039-3044. DOI: https://doi.org/10.5272/jimab.2020262.3039

Received: 10/06/2019; Published online: 01/04/2020

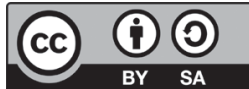

Address for correspondence:

Atanaska Spasova Dinkova, DMD, PhD

Oral surgery department, Faculty of dental medicine, Medical University

3 "Hristo Botev" blvd, Plovdiv, Bulgaria

Tel.: +359886711031

E-mail: dinkova_asia@yahoo.com 